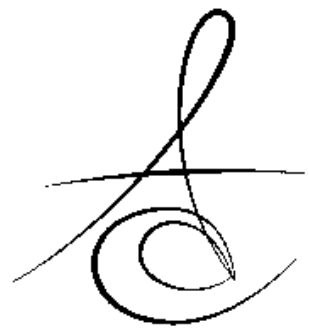

\title{
İMPLANT ÜSTÜ OVERDENTURE PROTEZLERDE TUTUCU BAŞLIK DEFORMASYONUNA ALTERNATİF BİR ÇÖZÜM YÖNTEMİ: BİR OLGU SUNUMU ${ }^{*}$
}

\section{AN ALTERNATIVE SOLUTION METHOD FOR DEFORMATION OF RETENTIVE CAPS IN IMPLANT SUPPORTED OVERDENTURE PROSTHESIS: A CASE REPORT ${ }^{*}$}

\author{
Dr. Öğr. Üyesi Bilal HOLOĞLU*
}

Prof. Dr. Zeynep YEŞİL DUYMUŞ**

Makale Kodu/Article code: 2743

Makale Gönderilme tarihi: 29.03.2016

Kabul Tarihi; $\quad 22.04 .2016$

\section{öz}

İmplant üstü overdenture protezler retansiyon ve stabiliteye olumlu katkılarından dolayı tam dişsiz hastaların yaşam kalitelerini artırmakta ve günümüzde standart bir tedavi protokolü olarak kabul edilmektedir. İmplant üstü overdenture protezlerde implantların üzerine topuz başlı ataşman, locator ataşman, barlı eklem veya mıknatıs gibi mekanizmalar yerleştirilerek tutuculuk sağlanmaktadır. Protezin içine kullanılan bağlantı mekanizmasına göre tutucu başlıklar yerleştirilmektedir. İmplant üstü overdenture protezlerin uzun dönem başarıları değerlendirildiğinde en sık karşılaşılan mekanik problemin tutucu başlıkların plastik yapılarındaki deformasyona bağlı retansiyon kaybı olduğu bilinmektedir. Çoğunlukla lastik yapıların yenilenmesi ile tutuculuk yeniden sağlanabilmektedir. Bu olgu sunumunda implant üstü overdenture protezindeki tutuculuk kaybı nedeniyle kliniğimize başvuran bir hastanın şikayetlerinin giderilmesine yönelik uygulanan alternatif yöntem hakkında bilgi verilmiştir.

Anahtar Kelimler: Overdenture, implant, topuz başlı ataşman

\section{ABSTRACT}

Nowadays implant supported overdenture dentures are accepted as a standard treatment protocol due to improving life quality of edentulous patients with their positive contribution on retention and stability. Some mechanisms such as ball attachment, locator attachment and magnet retained system might be used for providing retention of implant supported overdenture prosthesis. Retainer caps are placed according to the retention mechanism used in the prosthesis. It is known that the most common mechanical problem was loss of retention due to deformation of the plastic structures when the longterm success of implant overdenture prosthesis evaluated. Generally the retention can be restored again with renovation of plastic structures. In this case report information was provided on an alternative method applied for the removal of the patient's complaints due to loss of retention of implant supported overdenture prosthesis.

Keywords: Overdenture, implant, ball attachment

\section{GİRİŞ}

Son 40 yıldır dental implantlar, kısmi ve tam dişsiz hastaların tedavisinde rutin olarak kullanılmaktadır. ${ }^{1}$ İki implant destekli mandibular overdenture protezler retansiyon ve stabiliteye olumlu katlılarından dolayı tercih edilmektedir. ${ }^{2}$ Tüm olumlu özelliklerine rağmen implant üstü sabit protezlerle karşılaştırıldığında implant destekli overdenture protezlerin 4-10 kat daha fazla protetik komplikasyona açık oldukları rapor edilmiştir. ${ }^{3-6}$ İmplant üstü overdenture protezlerde implantların üzerine top ataşman, locator ataşman, barlı eklem veya mıknatıs gibi mekanizmalar yerleştirilerek tutuculuk sağlanmaktadır. ${ }^{7}$ Implant üstü

*Gaziosmanpaşa Üniversitesi Diş Hekimliği Fakültesi Protetik Diş Tedavisi AD, Eskişehir.

${ }^{* *}$ Atatürk Üniversitesi Diş Hekimliği Fakültesi Protetik Diş Tedavisi AD, Erzurum.

* 5.Uluslararası Türk Prostodonti ve İmplantoloji Derneği Bilimsel Sempozyumunda poster

(P.201643) olarak sunulmuştur 
overdenture protezlerde en sık karşılaşılan mekanik komplikasyonun tutucu başlıkların plastik yapılarındaki deformasyona bağı retansiyon ve stabilite kaybı olduğu bilinmektedir. ${ }^{2}$ Çoğunlukla lastik yapıların yenilenmesi ile tutuculuk yeniden sağlanmakladır. ${ }^{8}$ Günümüzde implant marka ve model sayısının artmasına bağlı olarak bazı durumlarda hastalara hangi implantın uygulanmış olduğu gerek klinik gerekse radyografik değerlendirme ile net olarak belirlenememektedir. İmplant markasının belirlenememesine bağlı olarak lastik parçaların temin edilemediği veya temin sürecinin uzun süreceği durumlarda retansiyon ve stabilitenin yeniden sağlanabilmesi amacıyla üreticiler tarafından silikon yapısında materyaller geliştirilmiştir. Üç farklı sertlik derecesine sahip bu materyaller tutucu başlıklar gibi protezin iç yüzeyine uygulanmaktadır. Bu olgu sunumunda protezlerinde tutuculuk ve stabilite kaybı nedeniyle kliniğimize başvuran bir hastanın overdenture implant üstü protezine tutuculuk ve retansiyonun yeniden kazandırımasına yönelik klinik ve laboratuar uygulamalarına ilişkin bilgi verilmiştir.

\section{OLGU SUNUMU}

Kliniğimize başvuran alt total üst Kennedy Sınıf I dişsizliğe sahip 53 yaşında erkek hastanın anamnezinde başka bir klinikte 12 yıl önce mandibular iki implant üzerine overdenture protez yaptırdığı belirlenmiştir. Mevcut protezlerindeki tutucu başlıkların zaman içerisinde deformasyona uğrayarak protez içerisindeki yuvalarından tamamen ayrıldığı tespit edilmiştir. Radyografik ve klinik değerlendirme ile implantların periimplanter durumu değerlendirilmiş implantların ağızda tutulmasına karar verilmiştir. Hastaya uygulanan implant markası radyografik ve klinik değerlendirme ile belirlenememiştir (Resim 1,2).

Hastaya yeni üst bölümlü alt total protez hazırlanmıştır. İmplantların retantif özelliklerini yeniden kazandırabilmek için implant ile protez arasında bağlantı sağlayan silikon retansiyon malzemesi (Bredent Retention.sil Set, Senden, Almanya) uygulamasına karar verilmiştir (Resim 3).

Hazırlanan alt total protezin implant bölgelerine, uygulanacak materyal için yeterli boşluk oluşturulmuştur (Resim 4). Akrilik protez kaidesi ile bağlantıyı artırmak için ilk olarak oluşturulan boşluğa üretici talimatları doğrultusunda set içerisinde bulunan Multisil-primer kendi uygulama fırçası ile 30 sn boyunca hazırlanan boşluk bölgelere uygulanmıştır. Üretici firma, set içerisinde bulunan üç farklı sertlikteki silikon bağlantı materyalinden retention.sil 200 için 6 ay, retention.sil 400 ve retention.sil 600 için 12-24 ay yenileme süresi önermiştir. Hastanın protezlerini uzun süreli kullanabilmesi için yenileme süreleri dikkate alınarak orta derecede retantif olan retention.sil 400 silikon bağlantı materyali uygulanmıştır (Resim 5). Hastaya protezler teslim edilmiş ve haftalık kontrollere çağrılmıştır (Resim 6). Kontroller esnasında hastanın tutuculuk beklentilerinin daha iyi sağlanabilmesi için orta sert yapıda uygulanan silikon bağlantı materyali üretici direktifleri doğrultusunda en yüksek tutuculuk sağlayan sert yapıdaki silikon bağlantı materyali ile değiştirilmiştir. Hastanın 3 ve 6. aylarda kontrolleri yapılmış herhangi bir şikayetinin olmadığı görülmüştür. Silikon bağlantı materyali ile protez kaide materyali arasındaki bağlantı ve renklenme görsel olarak değerlendirilmiş herhangi bir problem tespit edilememiştir. Hasta tekrar değerlendirilmek üzere 6 ay sonra kontrole çağrılmıştır.

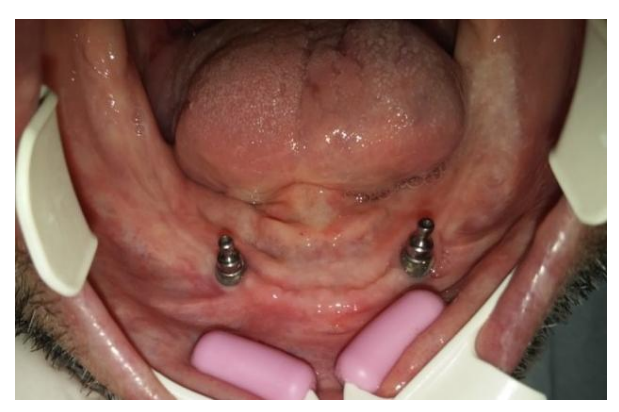

Resim 1.

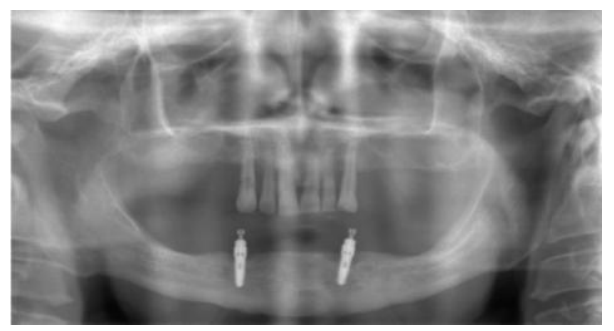

Resim 2. 


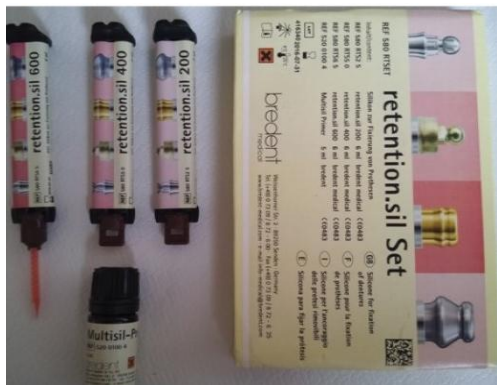

Resim 3.

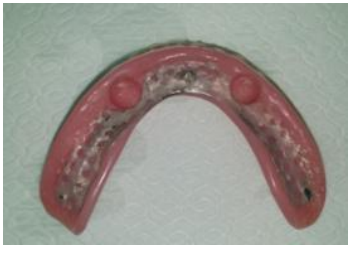

Resim 4.

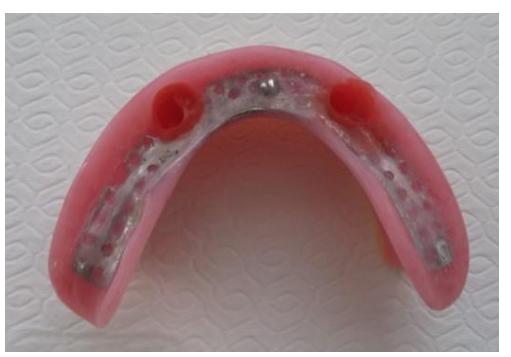

Resim 5.

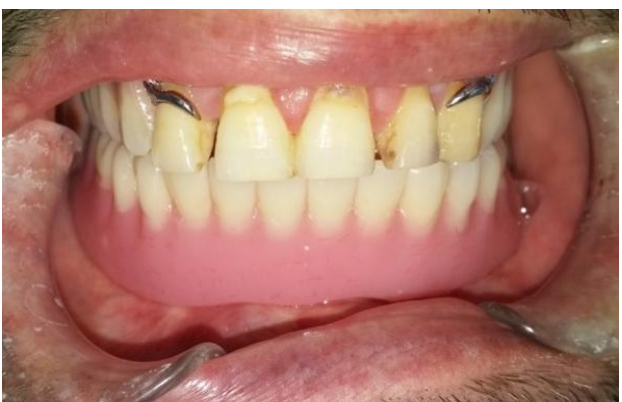

Resim 6. Bitmiş protezler

\section{TARTIŞMA}

İmplant üstü overdenture protezlerde en sık karşılaşılan mekanik komplikasyon gelişen tutuculuk ve stabilite kaybıdır. Retansiyon kaybı çoğunlukla kullanılan tutucu sistemiyle ilgilidir ve zaman içinde tutucu parçalarda meydana gelen esneme, aşınma, tutucu parçanın protez kaidesinden ayrılması, kırıma veya tutucu parçaların korozyona uğramasına bağı olarak gelişmektedir. ${ }^{5,6}$ Tutucu parçalardaki esneme ve aşınmaya bağlı gelişen tutuculuk kaybının giderilmesinde tutucu parçaların aktivasyonu veya yeniden değiştirilmesi gerekmektedir. ${ }^{9}$

Çakarer ve ark. ${ }^{10}$ top ataşman, bar-klips sistemi ve locator ataşman sistemlerini değerlendirdikleri çalışmalarında, top tutucu ve bar-klips sisteminin kullanııı̆ı̆ı vakalarda protez kırığı, klipslere ve o-ring ataşmanlara bağlı retansiyon kaybı ve ataşman kııkları saptamışlar, locator ataşmanlarda ise bu komplikasyonlara rastlanılmadığını bildirmişlerdir.

Tutucu parçaların protez retansiyonuna olumlu katkılarının uzun süreli devam edebilmesi temelde tutucu parçaların dayanıkılıklarına bağlıdır. Zaman içerisinde mekanik olarak deforme olan tutucu parçalar hasta memnuniyetini azaltmaktadır. Tutucu parçaların deformasyonu durumunda beklenmeden yenileri ile değiştirilmesi en uygun çözüm yolu olmakla beraber, bazı durumlarda tutucu parçaların temin edilememesi gibi problemler klinisyenleri zor durumda bırakmaktadır. Tutuculuğun yeniden sağlanması için tutucu parçalara alternatif olarak üretilen silikon bağlantı materyallerinin uygulanması kolaydır ve klinisyenler için pratik bir çözüm yöntemidir. Yumuşak astar materyali olarak da kullanılan polimerize silikonlar iki pat halinde bulunurlar. Bu patlar eşit miktarda karıştırıır ya da tabanca sistemi kullanılarak uygulanırlar. Oda ısısında sertleşen silikonların en büyük dezavantajı bağlayıcı ajan kullanımasına rağmen akrilik protez kaidesiyle zayıf bağlantı oluşturmalarıdır. Bunun yanı sıra temizleme ve polisaj işlemlerinin zor olmasına bağı olarak materyal yüzeyinde Candida ve mikroorganizma tutunumu görülmektedir. ${ }^{11}$

Tutucu parçaların deformasyonuna bağı olarak görülen tutuculuk ve stabilite kaybı, hareketli implant üstü protezlerin klinik başarısını olumsuz yönde etkilemektedir. İmplant üstü hareketli protez planlamalarında bağlantı tipinin doğru seçilmesinin yanı sıra tedavi sonrası hasta takiplerinin düzenli olarak yapılması önem arz etmektedir. 


\section{SONUÇ}

Silikon bağlantı materyallerinin uzun süreli klinik sonuçları ve mekanik özellikleri açısından literatürde henüz yeterli bir çalışma bulunmamakladır. İmplant üstü overdenture protezlerin tutuculuğunun geçici olarak temininde silikon bağlantı materyalleri kullanabilirler. Materyal hakkında yeni çalışmalara ihtiyaç duyulmaktadır.

Bilal Holoğlu: ORCID ID: 0000-0001-7469-0196

Zeynep Yeşil Duymuş: ORCID ID: 0000-0001-7162-8792

\section{KAYNAKLAR}

1. Cox JF, Zarb GA. The longitudinal clinical efficacy of osseointegrated dental implants: A 3 year report. Int J Oral Maxillofac Implants 1987;2: 91100.

2. Feine JS, Carlsson GE, Awad MA, Chehade A, Duncan WJ, Gizani S, Head T, Lund JP, MacEntee M, Mericske-Stern R, Mojon P, Morais J, Naert I, Payne AG, Penrod J, Stoker GT, Tawse-Smith A, Taylor TD, Thomason JM, Thomson WM, Wismeijer D. The McGill.consensus statement on overdentures as first choice standard of care for edentulous patients. Int J Oral Maxillofac Implants 2002; 601-2.

3. Canay Ş, Güncü MB. İmplant destekli overdenture protezlerde ortaya çıkan sorunlar. Türkiye Klinikleri J Prosthodont-Special Topics 2015;1:60-5.

4. Van Kampen F., Cune M., van der Bilt A., Bosman $F$. Retention and postinsertion maintenance of bar-clip, ball and magnet attachments in mandibular implant overdenture treatment: an in vivo comparison after 3 months of function. Clin Oral Implants Res 2003;14: 7206.

5. Cehreli MC, Karasoy D, Kökat AM, Akça K, Eckert S. A systematic review of marginal bone loss around implants retaining or supporting overdentures. Int J Oral Maxillofac Implants 2010; 25: 266-77.

6. Payne AG, Solomons YF. The prosthodontic maintenance requirements of mandibular mucosa- and implant-supported overdentures: a review of the literature. Int J Prosthodont
2000;13:238-43.

7. Öztük G, Çömlekoğlu MD, Sonugelen M. İmplant destekli hareketli protezlerde tutucu mekanizmaların klinik başarıya etkisi: Derleme. Ege Üniv Diş Hek Fak Derg 2013;34:11-6.

8. Ünver S, Bankoğlu G, Karakoca Nemli S. Dental implantlarda protetik komplikasyonlar. ADO Klinik Bilimler Dergisi 2012;6:1109-18.

9. Kaptein ML, De Putter C, De Lange GL, Blijdorp PA. A clinical evaluation of 76 implant-supported superstructures in the composite grafted maxilla. J Oral Rehabil 1999;26: 619-23.

10. Cakarer S, Can T, Yaltırık M, Keskin C. Comp-14. lications associated with the ball, bar and Locator attachments for implant-supported overdentures. Med Oral Patol Oral Cir Bucal 2011;1: 953-9.

11. Mccabe JF, Walls AWG. Applied Dental Materials. 8th ed, U.K:Blackwell Science; 2000: 108-114.

\section{Yazışma Adresi}

Prof. Dr. Zeynep YEŞİL DUYMUŞ

Atatürk Üniversitesi

Diş Hekimliği Fakültesi Protetik Diş Tedavisi

Anabilim Dalı, Erzurum

E Mail: zyesilz@hotmail.com 